\title{
The Haemorrhoids' Pathology: Epidemiological, Diagnostic, Therapeutic and Evolutionary Aspects
}

\author{
A. Coulibaly¹, R. Kafando², K. S. Somda1, C. Doamba², M. Koura3 ${ }^{3}$ C. C. Somé4, T. Ouédraogo ${ }^{5}$, S. Traoré2 \\ ${ }^{1}$ Gastroenterology Service of the University Hospital Centre Yalgado Ouédraogo (CHUYO), Ouagadougou, Burkina Faso \\ ${ }^{2}$ Surgery of CHUYO, Ouagadougou, Burkina Faso \\ ${ }^{3}$ Gastroenterology Service of the University Hospital Centre Sanou Sourou (CHUSS), Bobo-Dioulasso, Burkina Faso \\ ${ }^{4}$ Medicine Department of the Regional Hospital of Kaya, Kaya, Burkina Faso \\ ${ }^{5}$ Surgery of the Polyclinic Notre Dame de la Paix (PNDP), Ouagadougou, Burkina Faso \\ Email: coulibacar@yahoo.fr
}

How to cite this paper: Coulibaly, A., Kafando, R., Somda, K.S., Doamba, C., Koura, M., Somé, C.C., Ouédraogo, T. and Traoré, S. (2016) The Haemorrhoids' Pathology: Epidemiological, Diagnostic, Therapeutic and Evolutionary Aspects. Open Journal ot Gastroenterology, 6, 343-352.

http://dx.doi.org/10.4236/ojgas.2016.611037

Received: September 20, 2016

Accepted: November 26, 2016

Published: November 29, 2016

Copyright $\odot 2016$ by authors and Scientific Research Publishing Inc. This work is licensed under the Creative Commons Attribution International License (CC BY 4.0).

http://creativecommons.org/licenses/by/4.0/

Open Access

\begin{abstract}
Background: Hemorrhoidal disease is most frequently encountered in proctology affection; it is defined by signs or symptoms attributed to hemorrhoids. Its pathogenesis is based on old theories and vascular mechanical which are nevertheless based on the current therapeutic approach. General Aim of the Study: To study haemorrhoids' pathology in order to improve its management. Methodology: A retrospective cross-sectional study was conducted over a period of two (2) years from 1 January 2012 to 31 December 2013. Data were collected from outpatients records in hepato-gastroenterology and digestive surgery services at "Polyclinique Notre Dame de la Paix" in Ouagadougou (2294 files). Results: 140 cases of haemorrhoids were recorded during our study period. The frequency was $6.1 \%$ of consultations. Males predominated with $75.71 \%$ of patients (sex ratio $=3.12$ ). The average age was 39.58 years. Civil servants were most affected by this disease (60\%). Rectal bleeding was the most common reason of consultation (52.14\%). The crown shape was predominated (59\%). The frequency of external haemorrhoids was the highest (65.71\%) and stage 4 $(40.79 \%)$ was the most represented. Anal fissure was the proctologic pathology, the most associated to haemorrhoids (17.14\%). Medical treatment concerned $89.28 \%$ of patients with $69.6 \%$ of favorable short-term evolution. No instrumental treatment was performed. Surgical treatment consisted of $10.71 \%$ of patients and the technique used was the Milligan-Morgan performed under spinal anesthesia. The postoperative complications were mainly represented by anal intense pain and acute urinary retention. The healing period of wounds was on average 6 weeks. Conclusion: The hemorrhoid has often underestimated in our regions. The instrumental treatment is nonexistent and should take an important place; it must be an indication before surgery.
\end{abstract}




\section{Keywords}

Haemorrhoids, Epidemiology, Diagnosis, Treatment, Evolution, Burkina Faso

\section{Introduction}

The haemorrhoids (or haemorrhoidal disease) result from an alteration of the normal composition of haemorrhoids, responsible of internal and external varicose veins of the anus and rectum. It is the result of circulatory, mechanical and sphincter disorders [1].

It is a benign, intermittent affection even if its exact prevalence is difficult to assess. [2].

This prevalence varies between $4.4 \%$ and $86 \%$ [3] [4] [5] [6] according to the study population, the definition or the type of information collection (questionnaire surveys or systematic proctology examination).

Thus, the prevalence in United States was 4.4\% [6]. In the UK, the disease has been reported with an incidence of $13 \%-36 \%$ [7]. In Africa, hemorrhoids represented 38.5\% of ano-rectosigmoid disease in Gabon [8], 58.88\% of anorectal pathology in Bangui (CAR) [9] and 30.4\% of anorectal consultations in Mali [8].

In Burkina Faso, few studies have been conducted on the hemorrhoids. It was at the forefront of anorectal diseases according to a study of ano-rectoscopies which was evaluated to $29.6 \%$ in 1995 [5] and $60 \%$ in 2007 [10] [11].

The aim of our research was to study the epidemiology, diagnosis, treatment and outcomes of this disease in order to improve the management.

\section{Methods}

A retrospective and cross-sectional study was conducted over a period of two (2) years from 1 January 2012 to 31 December 2013.

The study reviewed outpatients' records in the service of Hepato-Gastroenterology and Digestive Surgery of "Polyclinique notre Dame de la paix" of Ouagadougou.

Patients' records of all ages and sex, who have consulted regardless of the stage of haemorrhoids disease during the study period, were included. The patients seen for haemorrhoids disease recurrence after treatment were excluded.

For each patient, epidemiological data, diagnostic, treatment and results were collected.

The analysis and data entry were performed on PC using the software Epi-Info French version office 2010.

\section{Results}

Over two (2) years, 2294 consultations were recorded in the services of hepato-gastroenterology and gastrointestinal surgery including 140 cases of haemorrhoids disease. The haemorrhoids represented $6.1 \%$ of consultations. 
The mean age was 58 and 39 years (range 10 - 75 years). A predominance of the 30 39 years age group was noted.

The average time for first consultation was 889.37 days (range 24 hours - 30 years).

The distribution of patients by sex, occupation and residence is summarized in Table 1.

The distribution of patients according to the reasons of consultation is summarized in Table 2.

Table 1. Distribution of patients by sex, occupation and residence.

\begin{tabular}{ccc}
\hline & Frequency & Percentage \\
\hline Sex & 106 & 75.71 \\
Male & 34 & 34.29 \\
Female & & \\
Profession & 84 & 60 \\
Civil servants & 17 & 12.14 \\
Students & 12 & 8.57 \\
Workers & 10 & 7.14 \\
Tradespeople & 9 & 6.43 \\
Housewives & 4 & 2.86 \\
Retired & 2 & 1.43 \\
Farmers & 2 & 1.43 \\
Others* & & \\
Residence & 127 & $90.71 \%$ \\
Urban & 13 & $9.29 \%$ \\
Rural & &
\end{tabular}

${ }^{\star}$ Others professions correspond to spiritual guide.

Table 2. Distribution of patients according to the reasons of consultation $(\mathrm{N}=140)$.

\begin{tabular}{ccc}
\hline Reasons for consultation & Effectives & Percentage (\%) \\
\hline Proctorrhagia & 73 & 52.14 \\
Constipation & 65 & 46.43 \\
Proctalgia & 57 & 40.71 \\
Anal discomfort & 40 & 28.57 \\
Anal pain & 29 & 20.71 \\
Anal prolapsus & 25 & 17.86 \\
Anal itching & 9 & 6.43 \\
Others & 52 & 37.14
\end{tabular}

* Other reasons for consultation were represented by the anal leakage, abdominal pain, ballooning, borborygmus, eructation, anorexia, nausea, sleep disorders and fever. 
The topography of haemorrhoids packages has been seen in 61 patients. We identified crown packages in 36 cases, unique package in 12 cases, triple packages in 9 cases and twin packages in 4 cases.

Anoscopy was performed in 30 patients (21.43\% of cases).

Twenty-four (24) patients (17.14\% of cases) carried additional tests such as rectoscopy and colonoscopy.

After the physical examination and paraclinical explorations, the type of haemorrhoids location, the associated stage haemorrhoidal disease and Proctological were specified:

- Eighty-two (92) cases or $65.71 \%$ of external haemorrhoidal disease.

- Sixty-six (76) cases or 54.28\% internal haemorrhoidal disease.

Both types of location were sometimes associated in some patients.

The distribution of patients according to the stage of haemorrhoidal disease has been shown in Table 3.

The distribution of patients according to proctological pathologies associated has been shown in Table 3.

Complicated shapes type of external haemorrhoidal thrombosis (22 cases or $15.71 \%$ ) and internal haemorrhoidal prolapse thrombosis ( 3 cases or $2.14 \%$ ) have been identified (Table 4).

A total of 125 patients ( $89.28 \%$ of cases) received medical treatment essentially consists of lifestyle changes, laxatives, topical, venotonic, non-steroidal anti-inflammatory drugs (NSAIDs) and analgesics.

In 15 patients ( $10.71 \%$ of cases), haemorrhoidectomy according to Milligan-Morgan

Table 3. Distribution of patients according to frequency of haemorrhoidal stage $(n=76)$.

\begin{tabular}{ccc}
\hline Diagnostic & Numbers & Percentage (\%) \\
\hline Haemorrhoid stage 4 & 31 & 40.79 \\
Haemorroid stage 1 & 18 & 23.68 \\
Haemorroid stage 2 & 17 & 22.37 \\
Haemorroid stage 3 & 10 & 13.16 \\
\hline
\end{tabular}

Table 4. Distribution of patients according to proctological associated pathologies $(n=140)$.

\begin{tabular}{ccc}
\hline Associated pathologies & Numbers & Percentage (\%) \\
\hline Any & 96 & 68.57 \\
Anal fissure & 24 & 17.14 \\
Scarred remnant of thrombotic hemorrhoid & 14 & 10 \\
Fistula & 3 & 2.14 \\
Others* $^{*}$ & 16 & 11.43 \\
\hline
\end{tabular}

${ }^{*}$ Other associated pathologies were represented by the diverticulum of the right colon, the small polyp transverse colon, hyper spasmodic colon, colitis erythematous right, the dolichocolon, hypertrophic papilla, the colpocele, erythematous proctitis, cecal lipoma, the friable and hemorrhagic bud tumor of the rectum. 
technique was practiced. These patients either haemorrhoidal stages 3 and 4, or complications like thrombosis of haemorrhoids were associated with anal fissure or anal fistula. This technique was associated with a sphincterotomy in six (6) patients, a fissurectomy in two (2) patients and fistulectomy in one (1) patient.

No instrumental treatment was undertaken.

The average hospital stay was 1.6 day (range 1 - 5 days).

Among patients who received only medical treatment $(\mathrm{n}=125)$ :

- 87 patients (69.6\%) had a favorable short-term evolutionary;

- 7 patients (5.6\%) had persistence of their symptoms at short-term;

- 31 patients $(24.8 \%)$ were redirected to a surgical management but they were not agreed;

- No case of immediate or late complications was reported.

In surgical patients $(\mathrm{n}=15)$ :

- Short-term complications were intense anal pain (4 cases), acute urinary retention (4 cases), and anal bleeding (3 cases);

- No case of late complications (delayed healing, anal stenosis, faecal and gas incontinence, infection and anal bleeding haemorrhoid recurrence) was reported;

- The average time of wound healing was six (6) weeks and ranged from four (4) and eight (8) weeks.

\section{Discussion}

This retrospective study used data that were not collected in a standardized way by the records' authors. Some data were inaccurate and others have not been sought by the authors. In addition, the high cost of private services (many people in the country aren't able to honor), is a limiting factor to the consultation and/or management. Our results cannot be extrapolated to the entire population of patients with hemorrhoidal disease. Nevertheless, our study retains its interest in relating an experience on a subject still insufficiently studied.

The incidence of haemorrhoids in our study was $6.1 \%$.

This low incidence is also found by DIALLO [8] DEMBELE [8] in Mali and KOB SAME [12] in Cameroon with respectively $1.07 \%, 2.66 \%$ and $10.7 \%$.

However, it remains higher in DE ALMEIDA [13] study in Brazil with 27.6\% and RISS [14] study in Austria with 38.93\%.

The low frequency in our study could be underestimated due to:

- The high cost of services in the private sector which limit access to consultation and treatment,

- Socio-cultural factors such as modesty, poor access to health centers and the poor information about this disease which prevents some patients to consult,

- The frequent use of traditional therapies than medical therapies.

Moreover, these differences in prevalence may be related to the sample size and context of studies.

A male predominance was noted in our study. It was also found in other African stu- 
dies [8] [11] [12], but also in Europe [15] and Asia [16]. Men are more likely to seek treatment than women.

The average age of 39.58 years found in our study was also noted in other African studies [8] [11] [17] and America [18]. This is similar with the literature that found it as a common pathology in adults [19] [20]. Pathology is rarely found in the [21] child.

The age thirty was the most represented among our cases, but also in other American studies [13] and Asia [16].

This frequency is, however, different from ZEITOUN [22] which is between 45 and 65 years.

Regarding the socio-professional activity, civil servants were most affected in our study (60\%), as well as in other African studies like DEMBELE's [11] with 42.5\%. People from this profession adopt a sitting or standing position during their work.

The frequency of these postures during the main activity of the patients was reported in other African studies: in DEMBELE's [11], 58.3\% worked in sitting and $41.7 \%$ in standing positions. DIALLO' [8] study showed that $58.6 \%$ adopted sitting and standing up $21.0 \%$; KOB SAME [12] noted $31 \%$ for sitting and $10.2 \%$ for standing up position.

In the literature [22] [23] the sitting and standing positions are key factors to the haemorrhoidal disease.

The majority of patients (90.71\%) lived in urban areas; this is consistent with the literature that states that the haemorrhoidal disease is linked to higher socioeconomic level and to city life [22].

The mean delay of consultation was 889.37 days with extremes of 24 hours and 30 years.

This long delay is due to the same reasons that impede the consultation [10] [22] [24]. Many of patients consulted after persistence or worsening symptoms despite a self-medication or traditional treatments.

Rectal bleeding was the main reason for consultation in our study, also to some Asian studies [16]. However, the African studies [8] [11] and European [15] rather noted a prevalence of anal pain.

In our findings, the most frequent topography haemorrhoidal packages was the crown (59\%) followed by the office at 3:00, 8:00 and 11:00 (8.2\%). In other African studies such as DEMBELE [11], it was rather the topography to 3 hours, 7 hours and 11 hours (70.8\%), classical topography found in the literature [22], followed by a 11 hours (14.1\%). The variability of distribution of haemorrhoids pedicles allows understanding that the location and the number of haemorrhoidal packages can vary [25]. The most frequent single packet is at 5 hours [23].

Thirty of our patients (21.43\%) received anoscopy, $17.14 \%$ a rectoscopy and a colonoscopy. These additional examinations have also been observed in other African studies: ano-rectoscopy in $69.2 \%$ of patients DEMBELE [11] and 54.6\% for DIALLO [8]. The diagnosis of haemorrhoids is mainly based on the endo-canal visual exploration (anoscopy) and you have to seek other complementary tests in case of doubt in search of associated pathology (rectoscopy colonoscopy) [23]. 
Our study found $65.71 \%$ of external haemorrhoids, this result is relatively close to other African studies like ATTIPOU study (Togo) [24] [25] [26] with 56.09\% of cases.

As for the internal haemorrhoids, $54.28 \%$ of patients were concerned. This result was lower in ATTIPOU study [26] that reported 33.75\% of internal haemorrhoids.

Permanent haemorrhoid prolapse (stage 4) was more common in our study. Some European studies, showed that stage 1 was the most frequent [14] than the stage 3; whereas [18] African studies found a predominance of stage 2 [26] or stage 3 [11]. All stages are therefore encountered at different frequencies.

These differences could be explained by measure used by primary score of haemorrhoids disease described by Goligher [27] [28] and used in the international literature. This score has the advantage of being easy to understand and apply. However it has many limitations [28].

For associated Proctologic pathologies, anal fissure predominated in our study. This prevalence was similar to KOB SAME study in Cameroon [12] with $16 \%$ and the DIALLO's [8] with $13.8 \%$. However, for other authors, the anusitis was the most represented [8] [11].

Moreover, in the literature, the fissure and fistula are the most Proctologic pathologies associated with hemorrhoids [23].

External thrombosis was in $15.71 \%$ of patients, and internal thrombosis $2.14 \%$ in our study. The frequency of external thrombosis is very low than the $51.21 \%$ found by ATTIPOU [26].

External haemorrhoids thromboses are more frequent [26] and the internal thromboses are rare [22].

In total, $10.71 \%$ of patients received surgical treatment in our study, frequency consistent with $10 \%$ of literature but relatively low compared to $53.9 \%$ in DIALLO' study [8] and 25.7\% in DE ALMEIDA [13].

This difference is probably partly due to the sample size and context of study. In our study, patients would be reluctant to surgery for fear of the intervention or because of incorrect information on the surgery (impotence risk).

Indications for surgery in our study were stages haemorrhoidal 3 and 4 alone or associated with a fistula thrombosis external and internal haemorrhoidal prolapse and external hemorrhoids associated with a fissure which is consistent with the literature [29].

A short-term favorable recovery was found in more than half of patients under medical treatment in our study (69.6\%) and in other African studies like ATTIPOU study [26] with $86.2 \%$.

According to the literature [3], medical treatment can provide symptomatic relief and reduce the possibility of recurrence.

Acute urine retention (AUR) was the common immediate complication in our study with four (4) cases and 27\% in other African studies like DEMBELE [11] in 19.2\% of patients and Diallo [8] in 2.4\%. It was the same for intense anal pain (27\%). Some authors from Asia, reported intense anal pain as most common complication with $40 \%$ in 
SYED study [16].

The AUR also noted in the literature, with multifactorial causes (pain, opioids, excessive fluid replacement during surgery, anesthesia) and affected $2 \%$ to $20 \%$ of operated by haemorrhoidectomy [22]; the authors defined it by retention requiring a catheterization in $0.5 \%$ to $53 \%$ of cases.

The causes of Anal pain are also multifactorial (sphincter spasm, thrombosis, fecal impaction) and found in the literature as an immediate complication [22]. It is very important after haemorrhoidectomy tripédiculaire [29].

The mean time for healing wounds (six weeks) is similar to other African studies such as KOUADIO (Ivory Coast) [30] with five (5) weeks. These durations are consistent with the literature [31] [32].

\section{Conclusions}

This study highlighted the epidemiology, diagnosis, treatment and outcome of haemorrhoidal disease from 140 cases.

A low frequency of consultation, probably underestimated in our regions, was found. The haemorrhoids, which is benign, is a disease of all ages and genders.

Its diagnosis mainly based on clinical examination sometimes requires the participation of the paraclinical. Patients consult especially in the acute phase of the disease for quick relief of their symptoms.

The instrumental treatment does not exist and should find a place here; it must be an indication before surgery.

Many prefer a medical treatment even in case of surgical indication, mainly because of the surgery itself and postoperative conditions.

Decision making and many actions are therefore mandatory for a better understanding and management of the disease.

\section{Ethical Approval}

The study protocol was not submitted to an ethics committee because we do not have it in our structure.

\section{References}

[1] Beylot, G. (2008) La maladie hémorroïdaire. Actualités Pharmaceutiques, 47, 43-46. https://doi.org/10.1016/s0515-3700(08)70262-3

[2] Senéjoux, A. (2011) Traitement médical de la pathologie hémorroïdaire. La Presse Médicale, 40, 927-930. https://doi.org/10.1016/j.lpm.2011.06.012

[3] Ganz, R.A. (2013) The Evaluation and Treatment of Hemorrhoids. Clinical Gastroenterology and Hepatology, 11, 593-603. https://doi.org/10.1016/j.cgh.2012.12.020

[4] Haas, P.A., Haas, G.P., Schmaltz, S. and Fox Jr., T.A. (1983) The Prevalence of Hemorrhoids. Diseases of the Colon \& Rectum, 26, 435-439. https://doi.org/10.1007/BF02556521

[5] Hyams, L. and Philpot, J. (1970) An Epidemiological Investigation of Hemorrhoids. American Journal of Proctology, 21, 177-193.

[6] Johanson, J.F. and Sonnenberg, A. (1990) The Prevalence of Hemorrhoids and Chronic 
Constipation. An Epidemiologic Study. Gastroenterology, 98, 380-386.

https://doi.org/10.1016/0016-5085(90)90828-O

[7] Loder, P.B., Kamm, M.A., Nicholls, R.J. and Phillips, R.K.S. (1994) Haemorrhoïds: Pathology, Pathophysiology, Aetiology. British Journal of Surgery, 81, 946.

https://doi.org/10.1002/bjs.1800810707

[8] Diallo, G., Sissoko, F., Maiga, M.Y., Traore, A.K., Ongoiba, N., Dembele, M., et al. (2003) La maladie hémorroïdaire dans le service de chirurgie B de l'hôpital du point G. Mali Medical, 18, 9-11.

[9] Assimbanda, S., Ignaleamoko, A., Mbelesso, P., Bobossi, G.S., Boua, N., Camego-Police, S.M., et al. (2004) La pathologie ano-rectale à Bangui en république centre africaine (RCA). Mali Medical, 19, 12-14.

[10] Sawadogo, A., Bonkoungou, P., Serme, A.K., Millogo, A., Andonaba, J.B., Kamboule, B.E., et al. (2007) La maladie hémorroïdaire au centre hospitalier Universitaire Souro Sanou de Bobo-Dioulasso (CHUSS) Burkina Faso. Médecine d'Afrique Noire, 54, 349-351.

[11] Dembele, K.S. (2009) Etude de la maladie hémorroïdaire dans le service de chirurgie générale de l'hôpital somine dolo de mopti. Thèse, Faculté de Médecine, de pharmacie et d'odontostomatologie, Mali, 99 p.

[12] Kob Same, D. (2008) Aspects cliniques et épidémiologiques de la maladie hémorroïdaire chez des adultes en milieu urbain à Douala. Thèse, Faculté de Médecine et de sciences biomédicales, Université de Yaoundé I., 118 p.

[13] De Almeida, S.G., Coutinho, P.C., Meyer, M.M.M., Sampaio, D.V. and Gomes Da Cruz, G.M. (2012) Surgical Complications in 2,840 Cases of Hemorrhoidectomy by MilliganMorgan, Ferguson and Combined Techniques. Journal of Coloproctology, 32, 271-290.

[14] Riss, S., Weiser, F.A., Schwameis, K., Riss, T., Mittlböck, M., Steiner, G., et al. (2012) The Prevalence of Hemorrhoids in Adults. International Journal of Colorectal Disease, 27, 215 220. https://doi.org/10.1007/s00384-011-1316-3

[15] Pigot, F., Siproudhis, L. and Allaert, F.A. (2005) Risk Factor Associated with Haemorrhoidal Symptoms in Specialized Consultation. Gastroentérologie Clinique et Biologique, 29, 1270-1274. https://doi.org/10.1016/S0399-8320(05)82220-1

[16] Syed Asad, A., Agha Taj, M., Jarwar, M., Imran, J., Siddique, A.J. and Ghafoor Dalwani, A. (2010) Outcome of the Rubber Band Ligation with Milligan Morgan Haemorrhoidectomy. Journal of Ayub Medical College, Abbottabad, 22, 56-60.

[17] Hrora, A., Raiss, M., Menfaa, M., Sabbah, F., Ahallat, M., AL Baroudi, S., et al. (2002) Hémorroïdectomie selon la technique de Milligan et Morgan (à propos de 200 cas). Maroc medical, 24, 8-10.

[18] Säenz, E.V., Esparza, J.P., Magro, P.M., Aguirre, J.P., Fernändez, F.A., Rosales, J.M., et al. (2006) Hemorrhoidal Disease in a Specialty Medical Disease. Revista de Gastroenterología de México, 71, 428-432.

[19] Pariente, A. (1999) Hémorroïdes. AKOS (TRAITE DE MEDECINE). Elsevier, Paris.

[20] Puig, P.L., Amsellem, A. and Barberot, V. (1989) La proctologie au quotidien. L'objectif Médical, 58, 5-9.

[21] Duhamel, J. (1972) Proctologie aux divers âges. Flammarion, Paris.

[22] Zeitoun, J.D., Lehur, P.A., Atienza, P. and De Parades, V. (2011) Pathologie hémorroïdaire: où en sommes-nous en 2011? Hépato-Gastro \& Oncologie Digestive, 18, 177-192.

[23] Denis, J., Ganansia, R. and Du Puy-Montbrun, T. (1999) Proctologie Pratique. 4th Edition, Masson, Paris. 
[24] N’Dri, N., Lohoues, M.J.K., Attia, K.A., Moustapha, M.J., Yassibanda, S., Bougouma, A., et al. (1994) La maladie hémorroïdaire en milieu hospitalier africain: à propos de 522 Cas colligés au CHU de Cocody. Médecine et Chirurgie Digestive, 23, 233-234.

[25] Thomson, W.H. (1975) The Nature of Haemorrhoids. British Journal of Surgery, 62, 542552. https://doi.org/10.1002/bjs. 1800620710

[26] Attipou, K., et al. (2003) Prise en charge chirurgicale des affections ano-rectales non malformatives au CHU-Tokoin de Lomé (Togo): à propos de 168 cas. Journal Africain de Chirurgie Digestive, 3.

[27] Goligher, J. (1985) Haemorrhoids or Piles. In: Goligher, J., Ed., Surgery of the Anus, Rectum and Colon, Baillière Tindall, London, 98-149.

[28] Abramowitz, L. (2008) Score de la maladie hémorroïdaire. Hépato-Gastro \& Oncologie Digestive, 15, 471-473.

[29] Abramowitz, L., Godeberge, P., et al. (2001) Recommandations Pour la pratique Clinique sur le Traitement de la maladie hémorroïdaire. Gynécologie Obstétrique \& Fertilité, 29, 942-951. https://doi.org/10.1016/S1297-9589(01)00246-6

[30] Kouadio, G.K., Kouao, J.A., Kouadio, L.N. and Turquin, H.T. (2004) Expérience de l'hémorroïdectomie selon MILLIGAN MORGAN en Côte d'Ivoire. Médecine d'Afrique Noire électronique, 51, 385-388.

[31] Mortensen, N. and Romanos, J. (1997) Hemorrhoids. In: Nicholls, R.J. and Dozois, R.R., Eds., Surgery of the Colon and Rectum, Churching Livingston, New York, 209-231

[32] Sielezneff, I., Salle, E., Bulgar, J.C., Brunet, C., Sastre, B. and Sarles, J.C. (1996) Suites opératoires précoces après hémorroidectomie (1134 cas). 11èmes Journées de la Société Française de Chirurgie Digestive. Annales de Chirurgie, 50, 929-943.

Submit or recommend next manuscript to SCIRP and we will provide best service for you:

Accepting pre-submission inquiries through Email, Facebook, LinkedIn, Twitter, etc.

A wide selection of journals (inclusive of 9 subjects, more than 200 journals)

Providing 24-hour high-quality service

User-friendly online submission system

Fair and swift peer-review system

Efficient typesetting and proofreading procedure

Display of the result of downloads and visits, as well as the number of cited articles

Maximum dissemination of your research work

Submit your manuscript at: http://papersubmission.scirp.org/

Or contact ojgas@scirp.org 